\title{
Alexithymia in Patients with Psoriasis: A Cross-Sectional Study from Ecuador
}

This article was published in the following Dove Press journal:

Psychology Research and Behavior Management

\author{
Ivan Cherrez-Ojeda $\mathbb{I}^{1,2}$ \\ Emanuel Vanegas (iD ${ }^{1,2}$ \\ Miguel Felix (iD) 1,2 \\ Sofia Cherrez (iD) 2,3 \\ Delia Suárez-Almendariz ${ }^{4}$ \\ Johana Ponton ${ }^{5}$ \\ Vladimir Preciado 6 \\ Edgar Ollague-Cordova ${ }^{7}$ \\ Enrique Loayza ${ }^{5}$ \\ 'Universidad Espíritu Santo, \\ Samborondón, Ecuador; ${ }^{2}$ Respiralab \\ Research Group, Guayaquil, Ecuador; \\ ${ }^{3}$ School of Medicine, University of \\ Heidelberg, Heidelberg, Germany; \\ ${ }^{4}$ Departamento de Dermatología, \\ Honorable Cuerpo Consular de Damas, \\ Durán, Ecuador; ${ }^{5}$ Departamento de \\ Dermatología, Hospital Luis Vernaza, \\ Guayaquil, Ecuador; ${ }^{6}$ Área de \\ Fototerapia, Hospital Luis Vernaza, \\ Guayaquil, Ecuador; ${ }^{7}$ Clínica \\ Dermatológica Ollague, Guayaquil, \\ Ecuador
}

Correspondence: Ivan Cherrez-Ojeda Universidad Espíritu Santo, Km. 2.5 vía La Puntilla, Samborondón 0901-952, Ecuador Tel +59345II455

Email ivancherrez@gmail.com
Objective: We designed this study to determine the frequency of alexithymia in Ecuadorian patients with psoriasis, as well as possible associations between demographic factors, disease severity, and treatment adherence.

Methods: A cross-sectional study involving 99 Ecuadorian patients with psoriasis was conducted. Multinomial logistic regressions were performed to ascertain whether age, gender, educational level, years with disease, psoriasis area and severity index (PASI) scores, and treatment adherence categories are prediction factors in patients with psoriasis to present alexithymia, possible alexithymia or no alexithymia.

Results: A total of 99 patients participated in the study with a gender distribution of $57.6 \%$ male, and an average age and years with disease of 48.3 and 7.4, respectively. Out of all patients, $33.3 \%$ presented alexithymia, and $22.2 \%$ possible alexithymia, as assessed by the Toronto Alexithymia Scale (TAS-20). The multiple regression model statistically significantly predicted the TAS-20 score from age, gender, educational level, years with psoriasis, PASI score and level of adherence $F(7,88)=4.171, \mathrm{p}=0.001$, adj. $\mathrm{R} 2=0.189$. Only having the highest educational level added statistical significance to the prediction of having a lower TAS-20 score, whilst the remainder variables did not.

Conclusion: We found a similar proportion of alexithymia, as well of average TAS-20 scores among Ecuadorian patients with psoriasis in comparison to previous studies. Only having the highest educational level was found to decrease the TAS-20 score. Age, gender, years with psoriasis, PASI score and level of adherence were not identified as factors that influence the TAS-20 score.

Keywords: Alexithymia, psoriasis, Latin America, treatment adherence

\section{Introduction}

Alexithymia is a personality trait characterized by a reduced ability to recognize and describe internal emotions, resulting in difficulty identifying feelings and distinguishing them from bodily sensations. ${ }^{1}$ This trait has been associated with several mental and health problems, and it is currently regarded as a factor that might influence treatment response across various medical conditions. ${ }^{2}$ The impaired emotion processing and affect regulating capacities related to alexithymia might lead to a reduced ability to adapt to stressful situations, thus leading to unhealthy behaviors such as sedentary lifestyle, poor nutrition, and alcohol abuse. ${ }^{3}$ Even though there is no clear answer yet on the prognostic risk of this personality trait, in a brief review of prospective studies it was found that approximately half of the analyzed studies reported statistically significant adverse effects on health outcomes related to alexithymia. ${ }^{4}$ 
In patients with psoriasis the prevalence of alexithymia has been estimated at 25-30\%, with higher disease burden, and levels of anxiety and depression, as well as impairment in quality of life and work productivity, when compared to patients without alexithymia. ${ }^{5,6}$ Although there is not a consensus regarding the exact role of alexithymia in psoriasis, most studies consistently suggest a link between this personality trait and worse quality of life, with associations to other psychiatric conditions such as anxiety and depression also described. ${ }^{5-8}$ Despite the possible influence of alexithymia on the management of psoriasis, reversibility of this condition has been evidenced in patients who reach high levels of disease control, highlighting the importance of proper screening for psychological conditions, as well as of adequate follow-up in this particular group of patients. ${ }^{9}$ However, despite the observed reversibility of alexithymia with adequate treatment of psoriasis, the question of the chronological relationship between both conditions remains unsolved. ${ }^{10}$

Although not all patients with psoriasis will present alexithymia, most studies have consistently found significant differences in the levels of alexithymia between patients with psoriasis and healthy controls. ${ }^{11}$ There is also evidence to suggest that the presence of the alexithymic trait in patients with psoriasis is associated with inferior self-management. ${ }^{12}$ Self-management encompasses by definition all the tasks that an individual must undertake to live well with a chronic condition, including gaining confidence to deal with medical and emotional management. ${ }^{12}$ As such, understanding the extent of alexithymia in patients with psoriasis could potentially lead to changes in the approach and management of these patients.

Based on the current knowledge, we hypothesize that the alexithymic trait might be related to a worse treatment adherence and higher disease severity in patients with psoriasis. Consequently, we designed this study to i) determine the frequency of alexithymia in Ecuadorian patients with psoriasis, ii) explore possible associations to specific demographic variables (age, gender, educational level), and iii) analyze the relationship between alexithymia and clinical parameters (years with psoriasis, disease severity and treatment adherence).

\section{Methods}

\section{Study Design}

This is a cross-sectional study involving 99 Ecuadorian patients with psoriasis. Patient demographics and clinical characteristics were reported. The presence of alexithymia, psoriasis area and severity index (PASI) as well as treatment adherence was analyzed. Patients were selected from public and private healthcare centers in Guayaquil, Ecuador, through convenience sampling. To be included, participants were required to have a diagnosis of psoriasis, either clinically or through biopsy, and be over 18 years of age. ${ }^{13}$ Patients with other dermatological diseases (such as atopic or contact dermatitis, lichen planus, tinea corporis, pityriasis rosea, etc.) and those with psychiatric diseases, language impairment, or who found it difficult to visualize the survey were excluded from the study. Before answering the questionnaires, patients were informed about the purpose of the study and their role in it. During the survey, patients completed the paper-printed questionnaires either by themselves or with the help of a previously trained health care provider (e.g., physician, nurse, or intern).

To assess the presence of alexithymia, the twenty-item Toronto Alexithymia Scale (TAS-20) was used, which has been previously validated in Spanish ${ }^{14,15}$ The TAS-20 cutoff scoring used was equal or less than 51, nonalexithymia; between 52 and 60 , possible alexithymia; and equal or greater than 61 , alexithymia. Internal consistency coefficients of the TAS-20 and each factor in our sample are shown on Supplemental Table S1.

With respect to disease severity, the PASI was applied. ${ }^{16,17}$ The intensity of erythema, desquamation, and induration was rated in a 5-point scale ( 0 indicates no involvement whilst 4 indicates severe characteristic). Furthermore, the degree of involvement on the four anatomical regions (BSA, body surface area) was represented in a numerical scale that ranged between 0 and 6 , as such, $1=1-9 \%, 2=10-29 \%, 3=30-49 \%$, $4=50-69 \%, 5=70-89 \%$, and $6=90-100 \%$. A cutoff value of 10 was used to define psoriasis severity, where those patients with a PASI score $\geq 10$ were considered to have moderatesevere psoriasis. ${ }^{18}$

Finally, the 1986 4-point Morisky Green Levine Medication Adherence Scale (MGLS) was used to determine the degree of treatment non-adherence. ${ }^{19}$ We used a dichotomous definition of adherence, with 0 points denoting perfect adherence and 1+ points indicating some level of non-adherence.

\section{Sample Size}

To calculate sample size, we used G*Power Version 3.0.10. Setting the input parameters for a medium effect size $\left(\mathrm{f}^{2}=0.15\right)$, an $\alpha$ error probability of 0.05 , a power of 0.80 and 6 predictor variables (age, gender, education 
level, years with disease, PASI score and level of adherence), the required sample size was 98 .

\section{Ethical Considerations}

This study was approved by the ethics committee Comité de ética e Investigación en Seres Humanos (CEISH). All participants signed a written informed consent prior to their voluntary participation in the study.

\section{Statistical Analyses}

Descriptive statistics were performed for demographic and clinical variables such as age, gender, years with disease, TAS-20 score, PASI and more.

We performed a standard multiple regression to predict the TAS-20 score based on multiple independent variables, namely, age, gender, education level, years with psoriasis, PASI score and level of adherence. For such purpose, we first tested for independence of residuals, a linear relationship between the dependent and each of the independent variables, equal error of variances, multicollinearity, unusual points and distribution of residuals.

\section{Results}

The sample comprised 99 patients with a gender distribution of $57.6 \%$ male and $42.4 \%$ female, whose average age and years with disease were $48.3, \pm 12.7 \mathrm{SD}$, and $7.4, \pm 9.7 \mathrm{SD}$ years, respectively. Out of all patients, 33.3\% presented alexithymia and $22.2 \%$ possible alexithymia (Table 1 ). The average TAS-20 and PASI score of the selected sample were $53.8, \pm 14.2 \mathrm{SD}$, and 10.2, $\pm 11.7 \mathrm{SD}$, respectively. With respect to disease severity and treatment adherence, most patients presented mild psoriasis $(69.7 \%)$ as well as some level of non-adherence (72.7\%). Descriptive statistics of the studied samples are best described in Tables 1, 2, and 3 .

\section{Multiple Regression}

A multiple regression was run to predict TAS-20 score from age, gender, education level, years with psoriasis, PASI score and level of adherence. Through partial regression plots and a plot of studentized residuals against the predicted values linearity was assessed. Independence of residuals was evident through a DurbinWatson statistic of 2.220. In addition, visual inspection of a plot of studentized residuals against unstandardized predicted values was consistent with homoscedasticity. Through variance inflation factor values lower than 10 and/or tolerance values greater than 0.1 multicollinearity issues were rejected. No studentized deleted residuals
Table I Demographic and Clinical Information of Surveyed Population $(n=99)$

\begin{tabular}{|c|c|}
\hline Characteristics & Value n (\%) \\
\hline \multicolumn{2}{|l|}{ Gender } \\
\hline Male & $57(57.6)$ \\
\hline Female & $42(42.4)$ \\
\hline \multicolumn{2}{|l|}{ Educational level } \\
\hline No education & $3(3.0)$ \\
\hline Primary school & $9(9.1)$ \\
\hline Secondary school & $44(44.4)$ \\
\hline University & $43(43.4)$ \\
\hline \multicolumn{2}{|l|}{ Marital status } \\
\hline Single & $28(28.3)$ \\
\hline Married & $5 I(51.5)$ \\
\hline Divorced & $7(7.1)$ \\
\hline Widow & $2(2.0)$ \\
\hline Consensual union & II (II.I) \\
\hline \multicolumn{2}{|l|}{ TAS-20 } \\
\hline Non-alexithymia & $44(44.4)$ \\
\hline Possible alexithymia & $22(22.2)$ \\
\hline Alexithymia & $33(33.3)$ \\
\hline \multicolumn{2}{|l|}{ Disease severity } \\
\hline Mild & $69(69.7)$ \\
\hline Moderate-Severe & $30(30.3)$ \\
\hline \multicolumn{2}{|l|}{ MGLS } \\
\hline Some level of non-adherence & $72(72.7)$ \\
\hline Perfect adherence & $27(27.3)$ \\
\hline
\end{tabular}

Notes: For the TAS-20, the cutoff scoring used was equal or less than 51 , nonalexithymia; between 52 and 60, possible alexithymia; and equal or greater than 61 , alexithymia. A PASI score $\geq 10$ was considered as moderate-severe psoriasis. For the MGLS, a score of 0 points denoted perfect adherence and I+ indicated some level of non-adherence.

Abbreviations: TAS-20, Toronto Alexithymia Scale; MGLS, Morisky Green Levine Medication Adherence Scale.

greater than $\pm 3 \mathrm{SD}$, no leverage values above 0.2 , and no values for Cook's distance over 1 were reported. Q-Q plots were characteristic of a normal distribution. The multiple regression model statistically significantly predicted the TAS-20 score, $F(7,88)=4.171, \mathrm{p}=0.001$, adj. $\mathrm{R}^{2}=0.189$. From the independent variables, only having university studies $(\mathrm{B},-16.51)$ contributed with statistical significance to the prediction $(\mathrm{p}=0.001)$ (Figure 1; Supplemental Table S2).

\section{Discussion}

Alexithymia is a personality trait considered as a risk factor for a variety of medical conditions, that may increase susceptibility to disease development. ${ }^{20}$ Previous publications assessing this personality trait in patients with rheumatoid 
Table 2 Mean TAS-20, PASI, and MGLS Scores of Surveyed Population

\begin{tabular}{|l|l|}
\hline Characteristics & Mean \\
\hline Age & 48.3 \\
\hline Years with disease & 7.4 \\
\hline TAS-20 & 53.8 \\
Factor I & 19.7 \\
Factor 2 & 13.21 \\
Factor 2 & 20.8 \\
\hline PASI & 10.2 \\
\hline MGLS & 1.5 \\
\hline
\end{tabular}

Notes: For the TAS-20, the cutoff scoring used was equal or less than 51 , nonalexithymia; between 52 and 60, possible alexithymia; and equal or greater than 6I, alexithymia. A PASI score $\geq 10$ was considered as moderate-severe psoriasis. For the MGLS, a score of 0 points denoted perfect adherence and I+ indicated some level of non-adherence.

Abbreviations: TAS-20, Toronto Alexithymia Scale; Factor I, difficulty identifying feelings; Factor 2, difficulty describing feelings; Factor 3, externally oriented thinking; PASI, Psoriasis Area and Severity Index Asthma; MGLS, Morisky Green Levine Medication Adherence Scale.

Table 3 Mean TAS-20 and Factor Scores According to Category of Alexithymia

\begin{tabular}{|l|l|}
\hline Category & Mean \\
\hline Non-alexithymia TAS-20 & 40.9 \\
Factor I & 13.1 \\
Factor 2 & 9.4 \\
Factor 3 & 18.3 \\
\hline Possible alexithymia TAS-20 & 55.8 \\
Factor I & 20.7 \\
Factor 2 & 13.2 \\
Factor 3 & 21.8 \\
\hline Alexithymia TAS-20 & 69.7 \\
Factor I & 27.9 \\
Factor 2 & 18.2 \\
Factor 3 & 23.5 \\
\hline
\end{tabular}

Notes: For the TAS-20, the cutoff scoring used was: equal or less than 51 , nonalexithymia; between 52 and 60 , possible alexithymia; and equal or greater than 61 , alexithymia.

Abbreviations: TAS-20, Toronto Alexithymia Scale; Factor I, difficulty identifying feelings; Factor 2, difficulty describing feelings; Factor 3, externally oriented thinking.

arthritis, psoriatic arthritis, and plaque psoriasis have estimated the prevalence at roughly one-third. ${ }^{21,22}$ In the case of patients with rheumatoid and psoriatic arthritis, alexithymia has been associated to higher levels of inflammatory indices such as erythrocyte sedimentation rate (ESR), and C-reactive protein (CRP), but does not appear to be correlated with demographic variables. ${ }^{21}$ On the other hand, in patients with plaque psoriasis, a significant relationship was

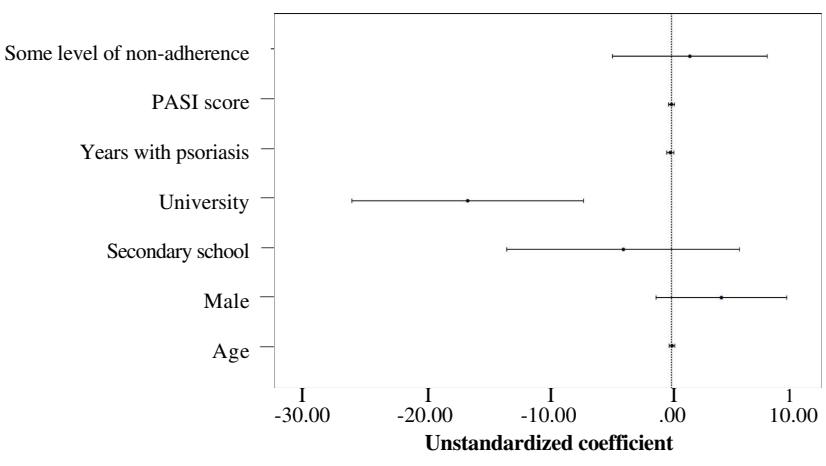

Figure I Regression coefficient plot with confidence intervals of standard multiple regression. Regression coefficients' names are placed in the Y-axis and their corresponding values express how they increase/decrease the TAS-20 score. Reference category for gender was "female"; reference category for education level was "no education"; reference category for level of adherence was "some level of nonadherence".

found between the female gender and the sensitive area of involvement. $^{22}$

In patients with psoriasis, previous studies have shown higher levels of alexithymia, as well as of average TAS-20 scores, when compared to healthy controls (52.62 \pm 13.46 , vs $39.63 \pm 10.21$, respectively). ${ }^{6,23}$ Similarly, in our study around a third of patients with psoriasis presented alexithymia, with comparable TAS-20 scores (average $53.8 \pm$ 14.2). ${ }^{6}$ In regards to Latin America, there is only one previous study in Mexico, where the alexithymic trait was identified in $25 \%$ of patients with psoriasis, and a correlation between alexithymia and anxiety scores was observed. $^{24}$ Whether alexithymia is related to the origin of psoriasis, or a consequence of the stigmatization associated with the disease, it profoundly affects the understanding and regulation of the inner states and emotions in these patients, hindering their coping mechanisms. ${ }^{7,24}$

Due to its psychological nature, it has been proposed that alexithymia might be the result of the interactions between biological and sociocultural factors. ${ }^{25}$ Biological theories suggest that alexithymia might be related to deficits in interhemispheric and limbic-neocortical communications, as well as possible dysfunction of the right cerebral hemispheres. ${ }^{25,26}$ In the case of sociocultural factors, poor education, and lowincome levels have been associated with higher frequency of alexithymia. ${ }^{27}$ In our study, from all the demographic variables analyzed in the multinomial regressions, only higher educational levels were found to be associated with lower levels of alexithymia when compared to patients with no education or primary school level. Albeit not a direct comparison, our result relates to a previous observation in which lower socioeconomic status (whether occupation, income, or educational 
level were used as the indicator) was associated with higher risk for mental illnesses such as depression, mania, dysthymia, and panic disorders. ${ }^{28}$

Furthermore, current evidence also suggests this personality trait is associated with worse quality of life. For instance, a large multicentric study found that alexithymic patients with psoriasis had significantly worse Dermatology Life Quality Index (DLQI) scores compared to their counterpart. ${ }^{5}$ In the case of disease severity, high PASI scores appear to be related with higher levels of interpersonal sensitivity but are inconsistent in mediation models when taking into consideration other variables such as the presence of alexithymia. ${ }^{7}$ In our study, we did not find a statistically significant association between PASI scores and the alexithymic trait. However, PASI scores might be useful for the follow-up of alexithymic patients with psoriasis, as reversibility of alexithymia has been evidenced in patients who reach high levels of disease control as defined by a PASI 75 or $90 .^{9}$

To our knowledge, this is one of the few studies to evaluate alexithymia in Latin American patients with psoriasis. However, the findings from our study should be seen in the light of several limitations. First, the cross-sectional design of this study prevents causality relationships to be drawn from our results. Second, we did not assess the quality of life or the dimension of negative affect by measures of anxiety and depression. Third, there is no control group in our study and therefore it is difficult to conclude whether alexithymia is or is not associated with psoriasis based on our data. Finally, there are sizable differences regarding the representation of the various educational level categories that should warrant attention in further studies.

\section{Conclusion}

In conclusion, we found a similar proportion of alexithymia, as well of average TAS-20 scores among Ecuadorian patients with psoriasis in comparison to previous studies. Only having the highest educational level was found to decrease the TAS-20 score. Age, gender, years with psoriasis, PASI score and level of adherence were not identified as factors that influence the TAS-20 score. Further studies are needed to determine the exact extent of this personality trait on the management of Ecuadorian patients with psoriasis.

\section{Abbreviations}

PASI, psoriasis area and severity index; TAS-20, Toronto Alexithymia Scale; BSA, body surface area; MGLS, Morisky Green Levine Medication Adherence Scale; DLQI, Dermatology Life Quality Index; SD, standard deviation.

\section{Ethics Approval and Consent to Participate}

This study was approved by the ethics committee Comité de ética e Investigación en Seres Humanos (CEISH), Guayaquil-Ecuador, in accordance to the principles established by the declaration of Helsinki.

\section{Data Sharing Statement}

The datasets used and/or analyzed during the current study are available from the corresponding author on reasonable request.

\section{Funding}

This work was funded and supported by Universidad Espiritu Santo. The sponsor had no role in the study design, data recollection or statistical analyses.

\section{Disclosure}

The authors declare no conflicts of interest related to this work.

\section{References}

1. Taylor GJ. Alexithymia: concept, measurement, and implications for treatment. Am J Psychiatry. 1984;141(6):725-732.

2. Lumley MA, Neely LC, Burger AJ. The assessment of alexithymia in medical settings: implications for understanding and treating health problems. J Pers Assess. 2007;89(3):230-246. doi:10.1080/ 00223890701629698

3. Lumley MA, Stettner L, Wehmer F. How are alexithymia and physical illness linked? A review and critique of pathways. J Psychosom Res. 1996;41(6):505-518. doi:10.1016/S0022-3999(96)00222-X

4. Kojima M. Alexithymia as a prognostic risk factor for health problems: a brief review of epidemiological studies. Biopsychosoc Med. 2012;6(1):21. doi:10.1186/1751-0759-6-21

5. Sampogna F, Puig L, Spuls P, et al. Prevalence of alexithymia in patients with psoriasis and its association with disease burden: a multicentre observational study. $B r \quad J$ Dermatol. 2017;176 (5):1195-1203. doi:10.1111/bjd.15243

6. Korkoliakou P, Christodoulou C, Kouris A, et al. Alexithymia, anxiety and depression in patients with psoriasis: a case-control study. Ann Gen Psychiatry. 2014;13(1):38. doi:10.1186/s12991-014-0038-7

7. Innamorati M, Quinto RM, Imperatori C, et al. Health-related quality of life and its association with alexithymia and difficulties in emotion regulation in patients with psoriasis. Compr Psychiatry. 2016;70:200-208. doi:10.1016/j.comppsych.2016.08.001

8. Luminet O, Bagby RM, Taylor GJ. Alexithymia: Advances in Research, Theory, and Clinical Practice. Cambridge University Press; 2018.

9. Sampogna F, Puig L, Spuls P, et al. Reversibility of alexithymia with effective treatment of moderate-to-severe psoriasis: longitudinal data from EPIDEPSO. Br J Dermatol. 2019;180(2):397-403. doi:10.1111/ bjd.2019.180.issue-2

10. Misery L. Alexithymia and psoriasis: what is the link? $\mathrm{Br}$ J Dermatol. 2019;180(2):261. doi:10.1111/bjd.2019.180.issue-2

11. Korkoliakou P, Efstathiou V, Giannopoulou I, et al. Psychopathology and alexithymia in patients with psoriasis. An Bras Dermatol. 2017;92(4):510-515. doi:10.1590/abd1806-4841.20175660

12. Larsen MH, Krogstad AL, Wahl AK. Alexithymia, illness perception and self-management competency in psoriasis. Acta Derm Venereol. 2017;97(8-9):934-940. doi:10.2340/00015555-2707 
13. Kim WB, Jerome D, Yeung J. Diagnosis and management of psoriasis. Can Fam Physician. 2017;63(4):278-285.

14. Bagby RM, Parker JDA, Taylor GJ. The twenty-item Toronto alexithymia scale-I. Item selection and cross-validation of the factor structure. J Psychosom Res. 1994;38(1):23-32. doi:10.1016/00223999(94)90005-1

15. Taylor GJ, Bagby RM, Parker JD. The 20-item Toronto alexithymia scale: IV. Reliability and factorial validity in different languages and cultures. J Psychosom Res. 2003;55(3):277-283. doi:10.1016/S00223999(02)00601-3

16. Fredriksson T, Pettersson U. Severe psoriasis-oral therapy with a new retinoid. Dermatologica. 1978;157(4):238-244. doi:10.1159/ 000250839

17. Ashcroft DM, Po WAL, Williams HC, Griffiths CE. Clinical measures of disease severity and outcome in psoriasis: a critical appraisal of their quality. Br J Dermatol. 1999;141(2):185-191. doi:10.1046/ j.1365-2133.1999.02963.x

18. Mrowietz U, Kragballe K, Reich K, et al. Definition of treatment goals for moderate to severe psoriasis: a European consensus. Arch Dermatol Res. 2011;303(1):1-10. doi:10.1007/s00403-010-1080-1

19. Morisky DE, Green LW, Levine DM. Concurrent and predictive validity of a self-reported measure of medication adherence. Med Care. 1986;24(1):67-74. doi:10.1097/00005650-198601000-00007

20. Baiardini I, Abba S, Ballauri M, Vuillermoz G, Braido F. Alexithymia and chronic diseases: the state of the art. G Ital Med Lav Ergon. 2011;33(1Suppl A):A47-A52.
21. Chimenti MS, Fonti GL, Conigliaro P, et al. Evaluation of alexithymia in patients affected by rheumatoid arthritis and psoriatic arthritis: a cross-sectional study. Medicine. 2019;98(4):e13955. doi:10.1097/ MD.0000000000013955

22. Talamonti M, Galluzzo M, Servoli S, D’Adamio S, Bianchi L. Alexithymia and plaque psoriasis: preliminary investigation in a clinical sample of 250 patients. Dermatology. 2016;232(6):648-654. doi:10.1159/000453661

23. Masmoudi J, Maalej I, Masmoudi A, et al. Alexithymia and psoriasis: a case-control study of 53 patients. L'Encephale. 2009;35(1):10-17. doi:10.1016/j.encep.2007.11.009

24. Torres-Hernández M, López-García S, Pedroza-Escobar D, EscamillaTilch M. El papel de la alexitimia como factor psicosomático en la psoriasis. Rev Med Inst Mex Seguro Soc. 2015;53(3):268-272.

25. Taylor GJ, Bagby RM, Parker JD. Disorders of Affect Regulation: Alexithymia in Medical and Psychiatric Illness. Cambridge University Press; 1999.

26. Nemiah JC. Denial revisited: reflections on psychosomatic theory. Psychother Psychosom. 1975;26(3):140-147. doi:10.1159/000286923

27. Pasini A, Delle Chiaie R, Seripa S, Ciani N. Alexithymia as related to sex, age, and educational level: results of the Toronto alexithymia scale in 417 normal subjects. Compr Psychiatry. 1992;33(1):42-46. doi:10.1016/0010-440X(92)90078-5

28. Aneshensel CS, Phelan JC, Bierman A. Handbook of the Sociology of Mental Health. Springer; 1999.
Psychology Research and Behavior Management

\section{Publish your work in this journal}

Psychology Research and Behavior Management is an international, peer-reviewed, open access journal focusing on the science of psychology and its application in behavior management to develop improved outcomes in the clinical, educational, sports and business arenas. Specific topics covered in the journal include: Neuroscience, memory and decision making; Behavior modification and management; Clinical

\section{Dovepress}

applications; Business and sports performance management; Social and developmental studies; Animal studies. The manuscript management system is completely online and includes a very quick and fair peer-review system, which is all easy to use. Visit http://www. dovepress.com/testimonials.php to read real quotes from published authors. 